\title{
Perspectives of Teachers and Administrators on the Use of E- School System at Schools
}

\author{
Mustafa Tuncay SARITAS*, Emel YILDIZ, \& Okan DURUSOY \\ Balikesir University, Balikesir, TURKEY
}

Received: $11 \cdot 10.2013$

Accepted: 11.12 .2013

\begin{abstract}
Parallel to rapid developments in Information and Communication Technologies, nowadays information now be reached only by itself does not constitute an essential element; besides this, it has become great importance of information processing, information production and especially via Internet, information marketing that all have entered in our lives. After 1990s, many countries started to take necessary arrangements and actions for the transformation of e-government. One of the e-transformation projects in Turkey, E-School Project, is school administration information software that was initiated in 2007 by Turkish Ministry of National Education (TMNE). It is crucial in terms of the effective use of this e-School system to determine the needs and demands of teachers and administrators who are active users of the system. The aim of this study is to evaluate the e-School system and put forward the potential improvements and changes on the design of this system by examining perspectives and perceptions of teachers and administrators. In this study, qualitative research methods and Atlas.ti text-based data analysis software were employed.
\end{abstract}

Key words: E-School, Information and Communication Technologies, perspectives of teachers and administrators

DOI No: http://dx.doi.org/10.12973/nefmed206

\section{Summary}

Introduction: Parallel to rapid developments in Information and Communication Technologies, nowadays information now be reached only by itself does not constitute an essential element; besides this, it has become great importance of information processing, information production and especially via Internet, information marketing that all have entered in our lives. In Turkey, as it is all over the world, public institutions and organizations

\footnotetext{
* Corresponding author: Mustafa Tuncay SARITAS, Dr. In Computer Education \& Instructional Technology, Necatibey Faculty of Education, Balikesir University, Balikesir, TURKEY.

E-mail: tuncaysaritas@gmail.com, tsaritas@balikesir.edu.tr
} 
have developed Internet-supported projects and new administrative implementations to strengthen decision support systems; to streamline business processes; and to increase efficiency and save money. In the 90s, many countries began to realize the necessary arrangements for e-government transformation.

Considering the target audience, the Ministry of Education in Turkey transferred its businesses and operations quickly to the Internet environment due to the realization of etransformation process. E-School, one of E-Transformation projects, is information system software for school management that was first initiated on January in 2007 by the Ministry of Education. This system includes the whole process of a student's actions from first school registration up to his/her graduation (e.g., absenteeism, progress report, examination, report cards, appreciation, etc.) . In addition, the school curriculum, course and teacher information as well as examination dates are all being processed easily within this e-school system.

E-school system is a system used by a large segment of society. Determining the needs and demands of teachers and administrators who input critical information; and conducting formative assessments of the system and updating it accordingly is vital for the effective use of this system. Another essential point related to the E-school system is about the need to focus on the design of this system. The purpose of this study is to investigate the perceptions and opinions of teachers and administrators working in primary schools about the use of eSchool system, and to evaluate the system and provide suggestions for possible adjustments on system's design.

Methodology: The population of the study consists of teachers and administrators working in primary schools in the province of Balikesir. The sample of the study includes 5 teachers of different branches (two-classroom teachers, the other three mathematics, social studies and music teachers) and 2 managers who have access to Internet at school and home.

The perceptions and opinions of teachers and administrators about e-school system were collected via semi-structured interviews. Prior to data analysis, the researchers translated voice-recorded interviews into electronic texts. A textual data analysis program, Atlas.ti, was used to determine codes by open coding method. Common codes then divided into five categories. These categories are: Purposes of the Use of the System, the Positive Aspects of the System, the Negative Aspects of the system, Imperfections in System Design, and Suggestions respectively. In terms of the reliability, the researchers conducted coding of the data separately at different times, and as a result of comparisons, the researchers-rater reliability was found as $84 \%$. 
Findings: In terms of intended use of the system by teachers and administrators, "grade input" is the most mentioned subject among others at a rate of $42.3 \%$. On the other hand, "student transfer procedures and reporting procedures" is the least subject area at $3.8 \%$. In addition, $57.1 \%$ of teachers and administrators said that the e-School system provides convenience for the recognition of students in detail.

The teachers and administrators while talking about the positive aspects of system put a great emphasize on the ease of access to information. $48.1 \%$ of them mentioned about ease of access to information; $18.5 \%$ about cost savings and $18.5 \%$ about time savings.

$71.4 \%$ of the teachers and administrators reported that the system from time to time becomes frozen due to many accesses at the same time. Among negative aspects of the system, $20.6 \%$ of teachers and administrators stated the problems and ambiguity with navigation through clickable icons and menus. $17.5 \%$ of those mentioned the lack of explanations within the systems, and 14.3 of those noted the need of components or parts in the system for help, site search and site map.

Results: E-school system is of great importance for a wide range of users. However, such a multi-user system ought to be designed and structured to be able to cater for all users who could do the different processes without experiencing any difficulties. After carefully examined the system design, there are various functions found to be uncertain to many users. Most of the time, the icons or menus necessary for some actions cannot be figured out by users. The menus were not ranked in order, which cannot be predicted from the menu bar that opens the intended page. System has a time limit of 10 minutes forcing the user been out of the system if no operation is performed. This situation affects the users, particularly the teachers, unhelpfully.

Suggestions: The Ministry of Education could do formative assessments to collect the opinions and/or feedbacks of teachers and administrators about e-school system from time to time. Designers could make some changes within the system in the light of these opinions. Based on this study, below are some suggestions for better use of the system:

- $\quad$ System design should be in more simple structure, and the menus and icons should be arranged in a more understandable manner.

- In order not to suffer timing problems, timers can be set to allow users to remain in the system longer. 
- Teachers and administrators have different technology skills and many of them are having difficulties in computer literacy. Due to this, in-service training sessions about the system could be organized and expanded the scope of the existing ones. .

- Against the crash of the servers depending on the level of intensive use of the system, software and hardware updates in proportion to needs and other necessary technical measures are important to be taken.

- Along with advanced site help module, site search and site map should be integrated.

- In order to minimize the problems in data inputs to the system, it should be rendered possible to transfer the contents of the files created by Office programs to the system.

- $\quad$ Plug-ins and other programs could be developed to enable the system work offline. Thus, many obstacles related to the Internet connection would be overcome.

- Rather than re-entering the data each time, updates or actions that can be done on the previously recorded data can provide the use even more momentum.

- Some of the modules in the system can be improved. For instance, there is a need in developing the module which is used to get a report about students.

- Some new modules can be integrated especially related to educational and instructional activities. 


\title{
E-Okul Sisteminin Okullarda Kullanılmasına İlişkin Öğretmen ve Yönetici Görüşleri
}

\author{
Mustafa Tuncay SARITAŞ ${ }^{\dagger}$, Emel YILDIZ, \& Okan DURUSOY
}

\author{
Balıkesir Üniversitesi, Balıkesir, TÜRKİYE
}

Makale Gönderme Tarihi: 11.10.2013

Makale Kabul Tarihi: 11.12 .2013

Özet - Bilgi ve iletişim teknolojilerindeki hızlı gelişmelere paralel olarak günümüzde artık bilgiye ulaşılması sadece kendi başına önemli bir unsur teşkil etmemekte bunun yanında bilginin işlenmesi, üretilmesi ve özellikle Internet vasıtasıyla bilginin pazarlanması süreçleri hayatımıza girmektedir. 90'lı yıllardan sonra dünya ülkeleri, gelişen teknolojilere bağlı olarak bilginin elde edilmesinden pazarlanmasına kadar olan paradigmaları ve yeni oluşumları gerçekleştirmek için kendi iç devlet mekanizmalarında "e-dönüşüm” yapılandırmalarını başlatmışlardır. Türkiye'de de E-Dönüşüm projelerinden “e-Okul projesi”, Milli Eğitim Bakanlığı bünyesinde 2007 yılında başlatılmış olan bir uygulamadır. Bu uygulama okul yönetim süreçlerini ve işlemlerini içeren bir bilgi sistemi yazılımıdır. Bu sistemde bilgi girişi yapan öğretmenlerin ve yöneticilerin ihtiyaç ve taleplerinin tespit edilmesi, sistemin belirli aralıklarla değerlendirme yapılarak güncellenmesi, sistemin etkin kullanımı açısından önemlidir. Bu çalışmanın amacı, henüz birkaç yıldır uygulanmaya başlanan e-Okul sistemini kullanan ilköğretim okullarında çalışan öğretmenlerin ve yöneticilerin, bu sistem hakkındaki genel algılarını ve sistemin tasarımı hakkındaki görüşlerini alarak, e-Okul sistemini değerlendirmek ve bu sistemin tasarımında yapılabilecek değişikleri ortaya koymaktır. Çalışmada nitel araştırma teknikleri ve veri analizi için Atlas.ti metin tabanlı veri analizi yazılımı kullanılmıştır.

Anahtar kelimeler: E-Okul, bilgi ve iletişim teknolojileri, öğretmen ve yönetici görüşleri

\section{Giriş}

Bilgi ve iletişim teknolojilerindeki hızlı gelişmelere paralel olarak günümüzde artık bilgiye ulaşılması sadece kendi başına önemli bir unsur teşkil etmemekte bunun yanında bilginin işlenmesi, üretilmesi ve özellikle Internet vasıtasıyla bilginin pazarlanması süreçleri hayatımıza girmektedir. İnternetin hemen her sektöre sağladığı olanaklar, yeni bir iletişim ve belli bilgileri içeren ortak bir iş platformu oluşturabilme ve bu platformda çalışabilme imkanı

\footnotetext{
† İletişim: Yard. Doç. Dr. Mustafa Tuncay SARITAŞ, Bilgisayar ve Öğretim Teknolojileri Eğitimi Bölümü, Necatibey Eğitim Fakültesi, Balıkesir Üniversitesi, Balıkesir, TÜRKIYE.

E-posta: tuncaysaritas@gmail.com, tsaritas@balikesir.edu.tr
} 
sağlamıştır. Bu durumun en büyük getirilerinden bir tanesi, farklı mekan ve zamanlarda bilgiye kaynağından ulaşılarak bilgi üzerinde hem maddi hem de zaman tasarrufu ederek mükerrer olmayacak düzenlemelerin yapılıp depolanabilir olmasıdır ki bu da özellikle şirket ve kamu kuruluşları için bilgiyi merkezileştirme olanağı sağlamaktadır. Dolayısıyla, bu platformdaki veya sistemdeki kullanıcılar doğru ve eksiksiz bilgiye erişebilmekte, karar alma süreçlerinde veri bütünlüğü sağlanarak daha hızlı ve doğru kararlar alınabilmektedir (DPT, 2005). Dünyadaki gelişmiş ülkelerdeki bu uygulamalara benzer şekilde ülkemizde de kamu kurum ve kuruluşları, yönetim ve karar destek sistemlerini geliştirmek, iş süreçlerindeki kalite kontrollerini ve denetlemelerini daha etkin, verimli ve hızlı bir şekilde gerçekleştirmek için toplumsal dönüşüme yani "Bilgi Toplumu"na zemin oluşturacak proje ve uygulamalar geliştirmişlerdir (DPT, 2006).

Ekonomik ve sosyal yaşam ile beraber toplumun her kesimini içine alan bu dönüşüm, İnternet teknolojisi vasıtasıyla “e-Devlet” ve “e-Dönüşüm” gibi kavramların doğmasına sebebiyet vermiştir. 90'l1 yıllardan sonra dünya ülkeleri, gelişen teknolojilere bağlı olarak bilginin elde edilmesinden pazarlanmasına kadar olan paradigmaları ve yeni oluşumları gerçekleştirmek için kendi iç devlet mekanizmalarında "e-dönüşüm” yapılandırmalarını başlatmışlardır. Kurumlar e-kuruma dönüşürken, sunmakta oldukları hizmetler bilgi ve iletişim ağlarına bağlı ortamlara taşınmıştır. Bu sayede, maliyetlerde düşüş ve yönetim ve organizasyon süreçlerindeki verimlilikte artış gözlenmiştir. Böyle bir artışı önceden tahmin edebilen ve buna yönelik uygulamaları başlatan devletler, bugün e-devlet dönüşümü ve dijital devrim yarışında lider rolü oynamaktadırlar (Arifoğlu, 2004. Akt: Aysin, 2007). Türkiye'nin bu yarıştan geri kalmaması ve yenilikçi teknolojileri modern yönetim ve tekniklerle birleştirerek bilgi toplumu durumuna gelebilmesi (Altıntaş, 2002) için tüm kurum ve kuruluşların hizmetlerini internet ortamına geçirmesi, yani “e-Dönüşüm Türkiye Projesi” yürütülmesi planlanmıştır. Bu projenin ana hedefi, toplumsal dönüşümün parçalarından olan vatandaşların, katılımcı, şeffaf, etkin ve basit iş süreçleri çerçevesinde daha kaliteli ve hızlı kamu hizmeti alabilecekleri bir devlet yapısının hazırlanmasıdır (DPT, 2006).

Toplumun her kesimine hitap eden Türkiye'nin en geniş çaplı resmi kurumlarından birisi olan Milli Eğitim Bakanlığı (MEB) e-dönüşüm faaliyetlerinin önemini kavramış ve bu doğrultuda çalışmalarını hızla başlatmış bir kurumumuzdur. MEB' nın başlattığı ilk uygulamalardan birisi, yönetimi tek noktadan yapılandırmaya olanak tanıyan "Millî Eğitim Bakanlığı Bütünleşik Yönetim Bilgi Sistemi (MEBBİS)”dir. Özellikle Bakanlık bünyesindeki 
birimlerin yönetimsel işlemleri, yürütülen tüm atama, sınav vb. işlemlere ait duyurular elektronik ortamda gerçekleştirilmek üzere yeniden yapılandırılmıştır (MEB, 2004).

MEB' nın kurum ve personel bilgilerinin yönetimi amacıyla kurmuş olduğu MEBBİS projesinin yapısına benzer şekilde okul ve öğrenci bilgilerinin de sistemli bir biçimde saklanıp ihtiyaç halinde kolaylıkla ulaşılabilmesi amacıyla "e-Okul projesi” başlatılmış ve "e-Okul Yönetim Bilgi Sistemi” adıyla 2007 yılında uygulamaya koyulmuştur. E-Okul sistemi, bir öğrencinin okula kaydından dosya bilgilerine; nakil işlemlerinden gelişim raporları ve almış olduğu notlara kadar okuldaki tüm öğrenim sürecini içermektedir. Bununla birlikte, ders programları, ilgili öğretmenlerin bilgileri, ve sınav tarihlerinin belirlenmesi gibi diğer işlemleri de e-Okul sistemi (bknz. Şekil 1) üzerinden yürütülebilmektedir.

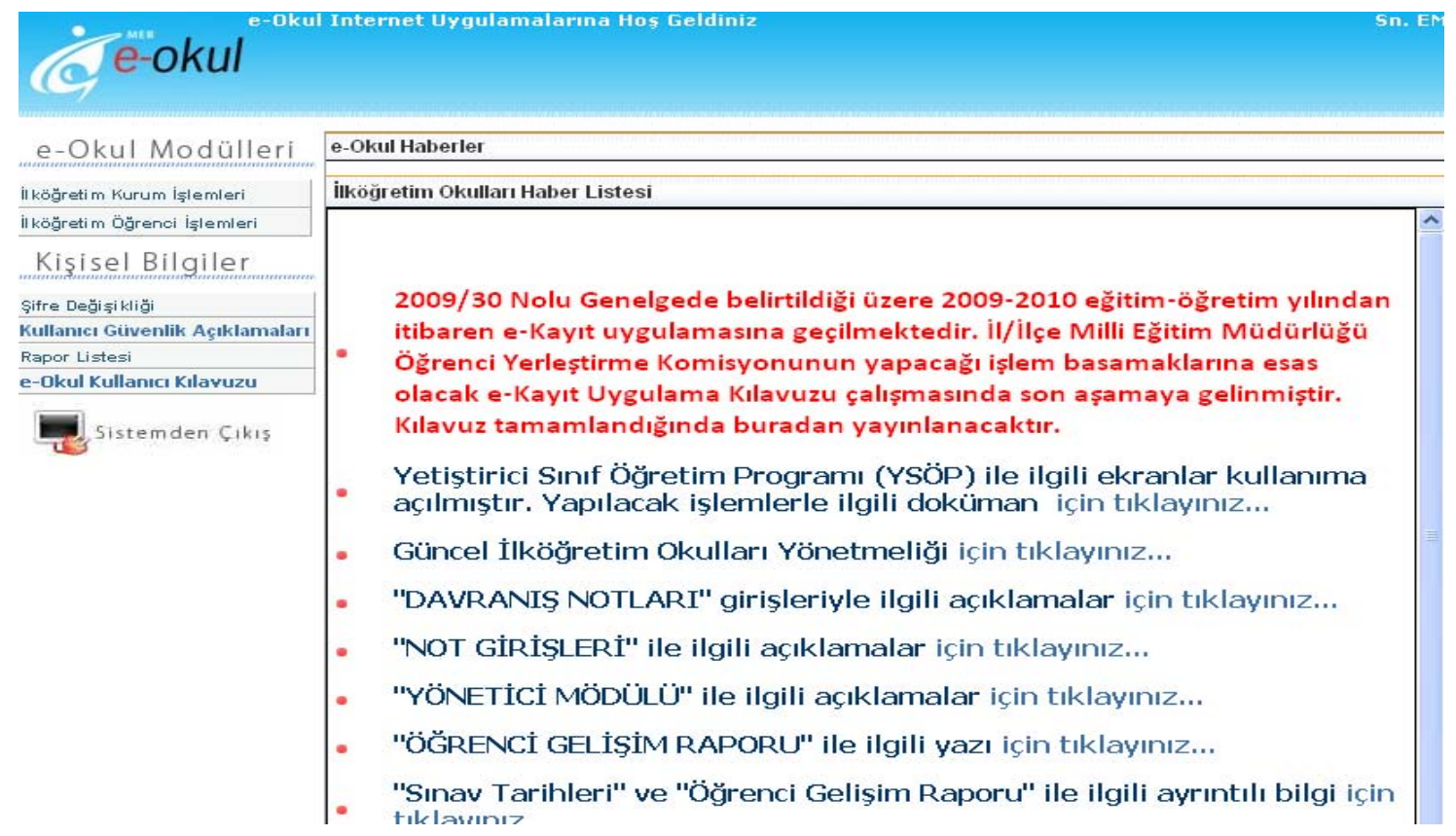

Şekil 1 E-okul Sistemi

E-Okul sistemini oluşturan 4 temel yapı vardır. Bunlar:

1. Öğrenci İşlemleri (bknz. Şekil 2) (Örn. Öğrenci dosya bilgilerinin saklanması ve ulaşılması, not ve devamsızlık bilgilerinin düzenlenmesi, öğrencilerin takibi, nakil ve ayrılma işlemleri) (MEB, 2007a),

2. Okul İşlemleri (bknz. Şekil 2) (Örn. Okula bilgilerin işlenmesi, öğrencilerin kaydının yapılması, sınıf ve şubelerin düzenlenmesi, öğretmenlerin bilgilerinin işlenmesi, okul nakil işlemlerinin yapılması, sosyal faaliyetlerin belirlenmesi, olumsuz davranışların kaydedilmesi) (MEB, 2007b), 
3. Milli Eğitim Müdürlükleri İşlemleri (Örn. Mezun olan öğrencilerin listesinin yapılması, il genelinde öğrenci başarısı değerlendirmesi ve sınav işlemlerinin yürütülmesi) (MEB, 2007c),

4. Bakanlık İşlemleri (Örn. Eğitim-öğretim takvimini oluşturma, öğrenci başarı değerlendirmesi, norm kadro tespiti ve kurum ile ilgili istatistiklerin oluşturulması) (MEB, 2007d).

\begin{tabular}{|c|c|c|}
\hline \multirow{4}{*}{ 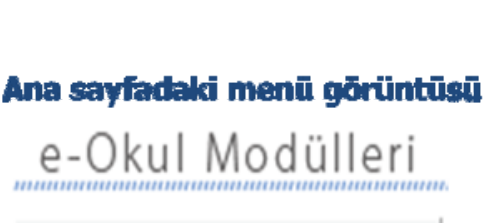 } & Kurum İşlemleri & Öğrenci İșlemleri \\
\hline & Eĕgitim Öğretim Dönemi: & Eğitim Öğretim Dönemi: \\
\hline & 2012-2013 II. Dönem V & 2012-2013 II. Dönem V \\
\hline & (ચ) Giriş Ekranı & Hızlı Öğrenci Arama \\
\hline il köğretim Kurum İşlemleri & Notlar ve Duyurular & T.C.Kimlik No okul No \\
\hline il köğretim Öğrenci İşlemleri - & ه Ders İ̧̧lemleri & Ara \\
\hline & Not işlemleri & Arama \\
\hline Tе & Sosyal Faaliyetler & Öğrenci Arama \\
\hline Şifre Değiş̧ kliği & (ه) Yöneltme iş̧lemleri & (₫) Ögrenci Dosya Bilgileri \\
\hline Kullanıcı Güvenlik Açıklamaları & \$ S.Ö.K işlemleri & (₫) Örenci Not Bilgileri \\
\hline & (7) Adey İşlemleri & Denklik ve Sınif Yükseltme \\
\hline Rapor Listesi & (ম) Okuduǒu Kitaplar & (₫aptirımlar \\
\hline e-0kul Kullanıcı Kılavuzu & Sinucugu Kitapiai & (8) Ögrencinin Aldığı Belgeler \\
\hline Sistemden Cikıs & Ana Menu & Ana Menu \\
\hline
\end{tabular}

Şekil 2 E-Okul Sistemi Bölümleri

Bahsi geçen bütün bu e-dönüşüm hareketleri hızlı bir şekilde gerçekleşmektedir. Öte yandan bu sürecin tam olarak yapılanması ve anlaşılması için gerek eğitimsel gerekse teknik altyapının güçlü olması, kurumların ise bu değişime ayak uydurabilecek şekilde iç süreçlerinin yeniden ele alınması gerekmektedir. E-Okul sistemi, toplumun büyük bir kesiminin kullandığı bir sistemdir. $\mathrm{Bu}$ sistemde bilgi girişi yapan öğretmenlerin ve yöneticilerin ihtiyaç ve taleplerinin tespit edilmesi, sistemin belirli aralıklarla değerlendirme yapılarak güncellenmesi, sistemin etkin kullanımı açısından önemlidir.

E-Okul sistemiyle ilgili üzerinde durulması gereken önemli noktalardan biri de bu sistemin tasarımıdır. Bu sistem web tabanlı olarak yürütülmektedir. Web tabanlı bir sistemin verimli bir şekilde işleyebilmesi için, web sitesinin tasarımına ayrıca önem verilmelidir. Site tasarımı kullanıcıya hitap edecek şekilde yapılandırılmalıdır. 
Tasarım kavramının iki önemli öğesi vardır. Bunlar; İnsan-Bilgisayar Etkileşimi ve Kullanılabilirlik kavramlarıdır. İnsan-Bilgisayar Etkileşimi, insan ile etkileşimli teknolojik araçların tasarımı, değerlendirilmesi ve uygulanmasına dönük farklı disiplinlerin bir arada çalıştığı bir bilim alanıdır (Acartürk ve Çağıltay, 2006). Kullanılabilirlik ise, bir teknolojik aracın kullanılmasında veya herhangi bir uygulamada gerçekleştirilmesi beklenilen işlerin veya işlevlerin kullanıcılar tarafından kolaylıkla ve etkili biçimde kullanılabilmesi olarak tanımlanabilmektedir (Nielsen, 1994). Bu açıdan bakıldığında bir tasarımın kullanılabilirlik derecesini etkileyen unsurlar; etkililik, verimlilik ve memnuniyettir (Çağıltay, 2005). Kullanıcı kitlesi fazla olduğu için e-Okul sitesinin tasarımı özenle yapılandırılmalıdır.

Kullanıcı arayüz tasarımında ve site tasarımında gözününde bulundurulması gereken noktalar ve kullanıcıların beklentileri aşağıdaki gibi bazı çalışmalar tarafından tespit edilmiştir:

Tablo 1 Arayüz ve site tasarımında kullanılabilirlik ve kullanıcı beklentileri

\begin{tabular}{|c|c|c|}
\hline $\begin{array}{c}\text { Kullanıcı Arayüz Tasarımı } \\
\text { (Nielsen, 1994) }\end{array}$ & $\begin{array}{l}\text { Site Tasarımı } \\
\text { (Oğuz, 2006) }\end{array}$ & $\begin{array}{c}\text { Kullanıcı Beklentileri } \\
\text { (Yılmaz, 2000) }\end{array}$ \\
\hline 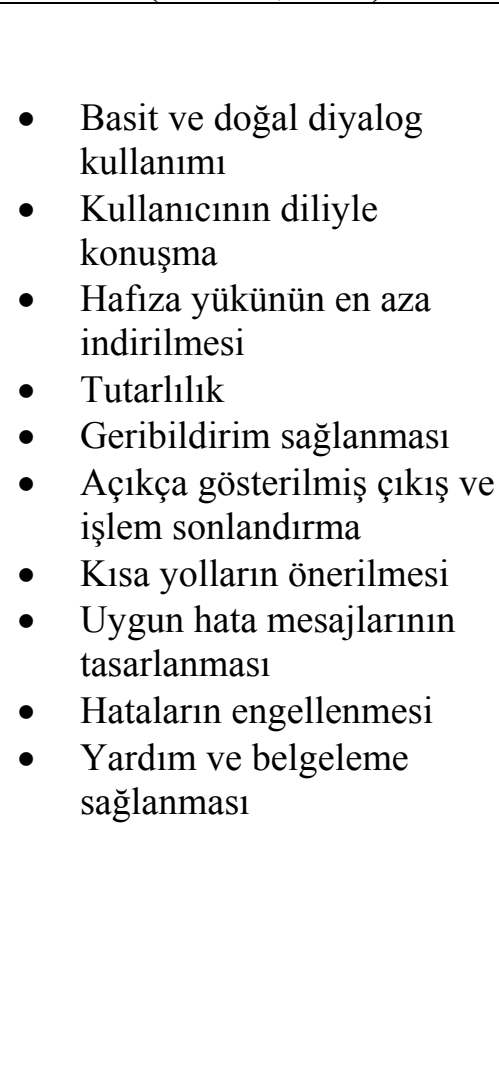 & $\begin{array}{l}\text { Kullanıcıların; } \\
\text { - } \quad \text { Teknik yeterlilik, } \\
\text { - } \quad \text { Web tecrübesi, } \\
\text { - } \quad \text { Kullanım sıklığı } \\
\text { - } \quad \text { Sistemden beklentileri } \\
\text { farklılık göstermektedir. } \\
\text { Bunun için, tasarım öncesinde; } \\
\text { - } \quad \text { Sitenin kullanıcı profili, } \\
\text { - Kullanıcıların siteden } \\
\text { beklentileri, } \\
\text { - Gereksinimleri, } \\
\text { - } \quad \text { Bilgisayar ve Web kullanım } \\
\text { seviyeleri, } \\
\text { - } \quad \text { Ara yüz kullanım tutumları } \\
\text { ve beklentileri, } \\
\text { - İhtiyaç duydukları } \\
\text { fonksiyonlar, } \\
\text { - Yazılım, donanım, bağlantı } \\
\text { hızı gibi sahip oldukları } \\
\text { teknik olanaklar vb. gibi } \\
\text { birçok konuda detaylı bilgi } \\
\text { edinilmelidir }\end{array}$ & $\begin{array}{ll}\text { - } & \text { Hız, hız ve daha fazla hız } \\
\text { - } & \text { Sade ve tutarlı sayfalar } \\
\text { - } & \text { Rahat kullanılabilirlik } \\
\text { - İçerik } \\
\text { - }\end{array}$ \\
\hline
\end{tabular}

$\mathrm{Bu}$ çalışmanın amacı, e-Okul sistemini kullanan ilköğretim okullarında çalışan öğretmenlerin ve yöneticilerin, bu sistem hakkındaki genel algılarını ve sistemin tasarımı 
hakkındaki görüşlerini alarak, e-Okul sistemini değerlendirmek ve bu sistemin tasarımında yapılabilecek değişikleri ortaya koymaktır.

\section{Yöntem}

Çalışmada nitel araştırma yöntemlerinden yarı yapılandırılmış görüşme tekniği kullanılmıştır. Görüşme, sözlü iletişim yoluyla veri toplama tekniğidir. "Görüşmede, söylenenlerin, yüzeysel anlamları yanında "gerçek" ve derinliğine anlamları çıkartılabilir." (Karasar, 2008, s.166)

\section{Katılımcilar}

Araştırmanın evrenini Balıkesir ilinde bulunan MEB' na bağlı ilköğretim okullarında görev yapan öğretmen ve yöneticiler oluşturmaktadır. Araştırmanın örneklemi belirlenirken, okulda ve evlerinde bilgisayar kullanma imkanı olan farklı branşlardaki öğretmen ve yöneticiler seçilmiştir. Örneklem; farklı branşlarda çalışan 2 yönetici ile 5 öğretmenden oluşmaktadır. Yöneticilerden biri görsel sanatlar, diğeri fen bilgisi öğretmenidir. Öğretmenlerden ikisi sınıf, diğerleri matematik, sosyal bilgiler ve müzik branş öğretmenleridir.

\section{Verilerin Toplanması}

Araştırma için veri toplamak amacıyla öncelikle alan ile ilgili literatür taranarak kuramsal yaklaşımlar incelenmiştir. Bu doğrultuda veri toplama aracı için madde havuzu oluşturmada yine alanla ilgili literatürden yararlanılmıştır.

Araştırmada yarı yapılandırılmış görüşme formu kullanılarak, öğretmen ve yöneticilerin e-Okul sistemi ile ilgili genel algıları ve bu sistemin tasarımı ile ilgili görüşleri alınmıştır. Yarı yapılandırılmış görüşmeler sırasında görüşmecilerin izni alınarak ses kayıt cihazı kullanılmıştır. Yarı yapılandırılmış görüşme formu literatür taraması temel alınarak a) Sistem Hakkındaki Algılar ve b) Sistemin Tasarımına İlişkin Görüşler olarak iki bölüme ayrılmış ve toplam 18 soru ile hazırlanmıştır. Birinci bölümde sistemle ilgili genel algılar, ikinci bölümde ise sistemin tasarımı ile ilgili sorular yer almıştır. Yarı yapılandırılmış görüşme formunda literatür taraması ile genel algıları belirlemek adına;

Sistemin;

$$
\checkmark \text { örneklem için ne ifade ettiği, }
$$




$$
\begin{aligned}
& \checkmark \text { hangi amaçlar için kullanıldığı, } \\
& \checkmark \text { mesleki açıdan onları nasıl etkilediği, } \\
& \checkmark \quad \text { olumlu ve olumsuz yönlerinin neler olduğu, } \\
& \checkmark \quad \text { daha etkin kullanımı için neler yapılabileceği gibi }
\end{aligned}
$$

örneklemin, sistem hakkındaki genel düşüncelerini alabileceğimiz 5 soru yöneltilmiştir.

İkinci bölümde tasarım ile ilgili görüşlerini almak için yine literatür taramasıyla elde edilen bilgiler 1şığında sitenin tasarımıyla ilgili 13 adet soru hazırlanmıştır.

Bu sorular;

Sitenin;

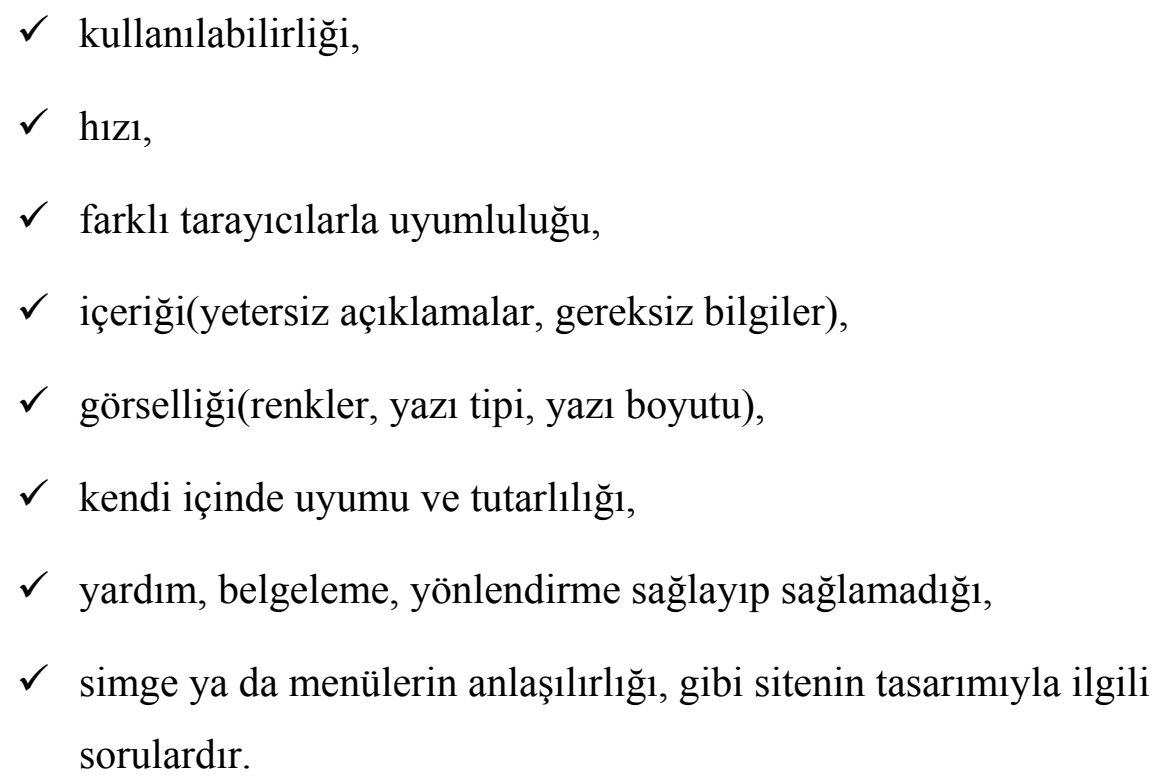

Sorularla alınmak istenen bilgiler yönetici ya da öğretmen için değişmemektedir. $\mathrm{Bu}$ yüzden yöneticilere ve öğretmenlere aynı sorular yöneltilmiştir. Görüşme soruları hazırlanırken literatür taraması yapılarak ve konuyla ilgili uzman görüşlerine başvurularak soruların hedeflenen amaçlara yönelik olması sağlanmıştır.

\section{Verilerin Analizi}

Yarı yapılandırılmış görüşme ile 2 yönetici ve 5 öğretmenden alınmış veriler nitel olarak incelenmiştir. Veri analizi öncesinde araştırmacılar kaydettikleri görüşmeleri elektronik metne çevirmiştir. Metne çevrilen görüşmeler ATLAS.ti metinsel veri analiz programına yüklenmiştir. Bu program vasıtasıyla açık kodlama yöntemi ile ortak kodlar belirlenmiştir. Ortak kodlar daha sonra beş kategoriye ayrılmıştır. Bu kategoriler; Sistemin Kullanım 
Amaçları, Sistemin Olumlu Yönleri, Sistemin Olumsuz Yönleri, Sistemin Tasarımındaki Olumsuzluklar ve Öneriler olarak belirlenmiştir. Bu kategoriler altında gruplanan kodlar ayrıntılı olarak ele alınmıştır. Mesela yapılan görüşme yönetici ile yapılmışsa tüm metin yönetici olarak, yapılan görüşme öğretmen ile yapılmışsa tüm metin öğretmen olarak kodlanmıştır. Veri analizinin geçerliği ve güvenirliği için araştırmacılar ayrı zamanlarda verileri paylaşıp ayrı ayrı kodlamaları yapmış, karşılaştırmalar sonucunda araştırmacılar-arası güvenirlik \%84 bulunmuştur. Araştırmacılar-arası yüzdelik uyuma bakıldığında, \%84 değerinin iyi derecede güvenirlik sağladığı tespit edilmiştir (Krippendorff, 2011 ve Neuendorf, 2002).

\section{Bulgular ve Yorumlar}

Öğretmenlerin görüşme sorularına verdiği yanıtlardan elde edilen verilerin frekans ve yüzdeleri alınmıştır. Veriler ortaya çıkan yığılmalar doğrultusunda yorumlanmıştır. Görüşme yapılan katılımcıların görüşme sorularına verdikleri yanıtların verileri-frekansları aşağıdaki tabloda yer almaktadir.

Tablo 2. Veri Frekansları

\begin{tabular}{|c|c|c|c|c|c|c|c|c|c|c|c|c|c|c|c|}
\hline \multirow{3}{*}{$\begin{array}{c}\text { Anket Maddelerine } \\
\text { Yönelik Kodlar } \\
\text { A. Sistemin Kullanım } \\
\text { Amaçları }\end{array}$} & \multicolumn{14}{|c|}{ Katılımcılar } & \multirow{3}{*}{$\begin{array}{c}\text { Toplam } \\
\mathrm{f}\end{array}$} \\
\hline & \multicolumn{2}{|c|}{ Yön1 } & \multicolumn{2}{|c|}{ Yön.2 } & \multicolumn{2}{|c|}{ Öğrt1 } & \multicolumn{2}{|c|}{ Öğrt2 } & \multicolumn{2}{|c|}{ Öğrt3 } & \multicolumn{2}{|c|}{ Öğrt4 } & \multicolumn{2}{|c|}{ Öğrt5 } & \\
\hline & $\mathrm{f}$ & $\%$ & $\mathrm{f}$ & $\%$ & $\mathrm{f}$ & $\%$ & $\mathrm{f}$ & $\%$ & $\mathrm{f}$ & $\%$ & $\mathrm{f}$ & $\%$ & $\mathrm{f}$ & $\%$ & \\
\hline 1. Not Girişi & 1 & 9 & 1 & 9 & 1 & 9 & 2 & 18.2 & 3 & 27.3 & 2 & 18.2 & 1 & 9 & 11 \\
\hline 2. Ayrıntılı Tanımak & 0 & 0 & 0 & 0 & 1 & 20 & 0 & 0 & 2 & 40 & 1 & 20 & 1 & 20 & 5 \\
\hline $\begin{array}{l}\text { 3. Okunan Kitap } \\
\text { Bilgileri }\end{array}$ & 0 & 0 & 0 & 0 & 0 & 0 & 1 & 25 & 2 & 50 & 1 & 25 & 0 & 0 & 4 \\
\hline $\begin{array}{l}\text { 4. Öğrenci Kayıt } \\
\text { İşlemleri }\end{array}$ & 1 & 50 & 0 & 0 & 0 & 0 & 1 & 50 & 0 & 0 & 0 & 0 & 0 & 0 & 2 \\
\hline 5. Sınav Başvuruları & 0 & 0 & 2 & 100 & 0 & 0 & 0 & 0 & 0 & 0 & 0 & 0 & 0 & 0 & 2 \\
\hline $\begin{array}{l}\text { 6. Öğrenci Nakil } \\
\text { İşlemleri }\end{array}$ & 1 & 100 & 0 & 0 & 0 & 0 & 0 & 0 & 0 & 0 & 0 & 0 & 0 & 0 & 1 \\
\hline 7. Karne İşlemleri & 0 & 0 & 0 & 0 & 0 & 0 & 1 & 100 & 0 & 0 & 0 & 0 & 0 & 0 & 1 \\
\hline $\begin{array}{c}\text { B. Sistemin Olumlu } \\
\text { Yönleri }\end{array}$ & $\mathrm{f}$ & $\%$ & $\mathrm{f}$ & $\%$ & $\mathrm{f}$ & $\%$ & $\mathrm{f}$ & $\%$ & $\mathrm{f}$ & $\%$ & $\mathrm{f}$ & $\%$ & $\mathrm{f}$ & $\%$ & $\mathrm{f}$ \\
\hline $\begin{array}{l}\text { 9. Bilgiye Erişim } \\
\text { Kolaylığ }\end{array}$ & 3 & 23.1 & 1 & 7.7 & 2 & 15.4 & 1 & 7.7 & 1 & 7.7 & 3 & 23.1 & 2 & 15.4 & 13 \\
\hline 10. Maddi Tasarruf & 1 & 20 & 0 & 0 & 0 & 0 & 0 & 0 & 0 & 0 & 2 & 40 & 2 & 40 & 5 \\
\hline 11. Zaman Tasarrufu & 1 & 20 & 0 & 0 & 2 & 40 & 0 & 0 & 0 & 0 & 0 & 0 & 2 & 40 & 5 \\
\hline $\begin{array}{l}\text { 12. İş Yükünün } \\
\text { Paylaşımı }\end{array}$ & 0 & 0 & 1 & 50 & 0 & 0 & 0 & 0 & 0 & 0 & 0 & 0 & 1 & 50 & 2 \\
\hline $\begin{array}{l}\text { 13. Hata Yapma } \\
\text { Olasılığı Azaldı }\end{array}$ & 0 & 0 & 0 & 0 & 2 & 100 & 0 & 0 & 0 & 0 & 0 & 0 & 0 & 0 & 2 \\
\hline $\begin{array}{c}\text { C. Sistemin Olumsuz } \\
\text { Yönleri }\end{array}$ & $\mathrm{f}$ & $\%$ & $\mathrm{f}$ & $\%$ & $\mathrm{f}$ & $\%$ & $\mathrm{f}$ & $\%$ & $\mathrm{f}$ & $\%$ & $\mathrm{f}$ & $\%$ & $\mathrm{f}$ & $\%$ & $\mathrm{f}$ \\
\hline 14. Server Yavaşlığ1 & 0 & 0 & 1 & 14.3 & 1 & 14.3 & 1 & 14.3 & 0 & 0 & 2 & 28.6 & 2 & 28.6 & 7 \\
\hline $\begin{array}{c}\text { D. Sistemin } \\
\text { Tasarımındaki } \\
\text { Olumsuzluklar }\end{array}$ & $\mathrm{f}$ & $\%$ & $\mathrm{f}$ & $\%$ & $\mathrm{f}$ & $\%$ & $\mathrm{f}$ & $\%$ & $\mathrm{f}$ & $\%$ & $\mathrm{f}$ & $\%$ & $\mathrm{f}$ & $\%$ & $\mathrm{f}$ \\
\hline $\begin{array}{l}\text { 15. Simge Ve } \\
\text { Menülerden Nereye }\end{array}$ & 2 & 15.4 & 1 & 7.7 & 5 & 38.5 & 2 & 15.4 & 2 & 15.4 & 1 & 7.7 & 0 & 0 & 13 \\
\hline
\end{tabular}




\begin{tabular}{|c|c|c|c|c|c|c|c|c|c|c|c|c|c|c|c|}
\hline $\begin{array}{l}\text { Ulaşılacağı Önceden } \\
\text { Tahmin Edilemiyor }\end{array}$ & & & & & & & & & & & & & & & \\
\hline $\begin{array}{l}\text { 16. Yetersiz } \\
\text { Açıklamalar }\end{array}$ & 1 & 9 & 0 & 0 & 5 & 45.5 & 0 & 0 & 5 & 45.5 & 0 & 0 & 0 & 0 & 11 \\
\hline $\begin{array}{l}\text { 17. Yardım, Site İçi } \\
\text { Arama, Site Haritası } \\
\text { Gibi Bölümlere İhtiyaç } \\
\text { Duyuyor }\end{array}$ & 2 & 22.2 & 0 & 0 & 2 & 22.2 & 2 & 22.2 & 1 & 11.1 & 1 & 11.1 & 1 & 11.1 & 9 \\
\hline $\begin{array}{l}\text { 18. Gereksiz Bilgiler } \\
\text { Var }\end{array}$ & 2 & 33.3 & 0 & 0 & 1 & 16.7 & 0 & 0 & 1 & 16.7 & 2 & 33.3 & 0 & 0 & 6 \\
\hline $\begin{array}{l}\text { 19. Hatanın } \\
\text { Giderilmesine Yönelik } \\
\text { Çözüm Yolu } \\
\text { Sunulmuyor }\end{array}$ & 2 & 40 & 0 & 0 & 1 & 20 & 1 & 20 & 1 & 20 & 0 & 0 & 0 & 0 & 5 \\
\hline $\begin{array}{l}\text { 20. Site Genelinde } \\
\text { Paylaşılan Elemanlar } \\
\text { Uyumsuz }\end{array}$ & 0 & 0 & 0 & 0 & 4 & 80 & 0 & 0 & 1 & 20 & 0 & 0 & 0 & 0 & 5 \\
\hline 21. Çıkışta Sorun Var & 1 & 25 & 0 & 0 & 1 & 25 & 0 & 0 & 1 & 25 & 1 & 25 & 0 & 0 & 4 \\
\hline $\begin{array}{l}\text { 22. Sayfanın Yavaş } \\
\text { Yüklenmesi }\end{array}$ & 2 & 50 & 0 & 0 & 1 & 25 & 0 & 0 & 1 & 25 & 0 & 0 & 0 & 0 & 4 \\
\hline $\begin{array}{l}\text { 23. Kaydetme Ve Çıktı } \\
\text { Alma Konularında } \\
\text { Yönlendirme Yok }\end{array}$ & 1 & 25 & 0 & 0 & 1 & 25 & 2 & 50 & 0 & 0 & 0 & 0 & 0 & 0 & 4 \\
\hline $\begin{array}{l}\text { 24. Dikkat Dağıtıcı } \\
\text { Öğeler Var }\end{array}$ & 1 & 50 & 0 & 0 & 1 & 50 & 0 & 0 & 0 & 0 & 0 & 0 & 0 & 0 & 2 \\
\hline $\begin{array}{l}\text { 25. İnternet Explorer } \\
\text { Dişındaki Tarayıcılarla } \\
\text { Uyumsuz }\end{array}$ & 0 & 0 & 1 & 50 & 1 & 50 & 0 & 0 & 0 & 0 & 0 & 0 & 0 & 0 & 2 \\
\hline E. Öneriler & $\mathrm{f}$ & $\%$ & $\mathrm{f}$ & $\%$ & $f$ & $\%$ & $\mathrm{f}$ & $\%$ & $\mathrm{f}$ & $\%$ & $\mathrm{f}$ & $\%$ & $\mathrm{f}$ & $\%$ & $\mathrm{f}$ \\
\hline $\begin{array}{l}\text { 26. Süre Sayaçlarının } \\
\text { Düzenlenmesi } \\
\text { İsteniyor }\end{array}$ & 0 & 0 & 1 & 25 & 2 & 50 & 0 & 0 & 0 & 0 & 0 & 0 & 1 & 25 & 4 \\
\hline $\begin{array}{l}\text { 27. Tasarımda } \\
\text { Düzenlemeye } \\
\text { Gidilmesi İsteniyor }\end{array}$ & 4 & 36.4 & 1 & 9.1 & 2 & 18.2 & 0 & 0 & 4 & 36.4 & 0 & 0 & 0 & 0 & 11 \\
\hline 28. Seminer Verilmeli & 3 & 75 & 0 & 0 & 1 & 25 & 0 & 0 & 0 & 0 & 0 & 0 & 0 & 0 & 4 \\
\hline
\end{tabular}

Sistemin kullanım amaçları arasında \%42.3 oranında öğretmen ve yöneticilerin en çok bahsettikleri konu not girişi' dir. Sistemin kullanım amaçları arasında en az bahsedilen \%3.8 oranında öğrenci nakil işlemleri ve karne işlemleri’dir. Ayrıca öğretmen ve yöneticilerin \%57.1’i e-Okul sisteminin öğrenciyi ayrıntılı olarak tanımayı sağladığını söylemişlerdir.

Öğretmen ve yöneticilerin tümü sistemin olumlu yönlerini anlatırlarken bilgiye erişim kolaylığına vurgu yapmışlardır. Bir öğretmen (öğretmen3) bilgiye erişim kolaylığından şu şekilde bahsetmiştir: "E-okul sisteminin devreye girmesiyle artık ögrencileri, onların not girişleri olsun okudukları kitaplar olsun aileler hakkında bilgiler olsun daha rahat daha güzel bir şekilde ulaşmamızı sağllyor. Onun dışında daha önceki sistemlerde bu tür bilgilere bir anda toplu bir şekilde ulaşmamı çok zor oluyordu. Fakat e-okul sisteminin devreye girmesiyle daha kolay bir şekilde bunlara ulaşıyoruz.” \% 48.1 oranında bilgiye erişim kolaylığından, \%18.5 oranında maddi tasarruf ve yine \%18.5 oranında zaman tasarrufundan bahsetmişlerdir. 
Öğretmen ve yöneticilerin \%71.4'ü sistemdeki yoğunluktan dolayı sistemin zaman zaman kilitlendiğinden bahsetmişlerdir. Server yavaşlığından kaynaklanan bu olumsuzluğu bir öğretmen (öğretmen4) şu şekilde dile getirmiştir: "Bazı zamanlarda not girişleri esnasında tüm ögrretmenlerin bilgisayara giriş için yüklenmesiyle hatlardaki aksaklıkların meydana gelmesi. Aşırı yüklenmeden kilitlenmeler oluyor ve bu şekilde zorlukları da olabiliyor."

Sistemin tasarım olumsuzlukları arasında \%20.6 oranında öğretmen ve yöneticilerin en çok bahsettikleri tasarım olumsuzluğu simge ve menülerden hangi sayfalara ulaşılacağının belli olmamasıdır. Bu tasarım olumsuzluğunu bir öğretmen (öğretmen1) şu şekilde ifade etmiştir: "Mesela sistem ögrenci işlemleri ve kurum işlemleri diye iki ana bölümden ve birçok alt bölümden oluşuyor. Ben hangi işin öğrenci işi, hangi işin kurum işi olduğunu tam ayıramadım. Sonuçta iki bölümü de biz kullanacağız. Üst tarafta bir yazıcı simgesi var orayı tıklayınca sayfayı yazdırmak yerine ekran raporları adında yeni bir menü çıkıyor. Bu özelliği de yeni buldum. Öğrencilere sınav tarihlerini duyurmak için kurum işlemleri bölümünün not girişleri menüsüne oradan da sınav tarihleri bölümüne girmemiz lazım. Bunu bulmak veya bilmek mümkün değil. Hala bazı ögrretmen arkadaşlar nasıl kullanılacă̆ını bana soruyorlar. Menüler çekmece rafi gibi üstüne tıklayınca açıldı̆̆ı için içinde ne var bilmiyoruz, yeterli açıklama da yok zaten." Ardından \%17.5 oranında açıklamaların yetersizliğinden ve 14.3 oranında yardım, site içi arama ve site haritası gibi bölümlere ihtiyaç duyulduğundan bahsedilmiştir. En az bahsedilen tasarım olumsuzlukları \%3.2 oranıyla dikkat dağıtıcı öğelerin varlığı ve yine aynı oranda bahsedilen, sistemin İnternet Explorer dışındaki tarayıcılarla uyumsuz olduğudur.

E-Okul sisteminde yapılabilecek değişiklikler için öneriler kısmında \%57.9 oranıyla en çok istenen tasarımda düzenlemeye gidilmesidir. Site tasarımının farklı yerlerinde düzenlemeler istenmektedir. Örneğin yönetici1 "Kullanmadı̆̆ın bazı bilgiler işlem yaptı̆̆ın sayfada bulunabiliyor. Mesela ders programıyla ilgili bilgileri girerken sayfanın ortasın da küçük bir ekran açıllyor ama onun dışında o an kullanmayacağın farklı dosyalar da mevcut. Karne doldururken de aynı durum var. Tam ekran olması belki daha iyi olabilir. Sonuçta karne dolduruyorsun diğer erişimlerle hiçbir ilgin yok." diyerek işlem ekranlarında düzenleme isterken, öğretmen2 "Bence ögretmenler için, yöneticiler için, ögrenciler için ayrı bir modül oluşturulabilirdi." diyerek farklı kullanıcılara farklı ara yüzlerin olmasını istemektedir. 


\section{Sonuç ve Öneriler}

\section{Sonuçlar}

E-Okul sistemi sahip olduğu geniş kullanıcı kitlesi ile büyük öneme sahiptir. MEB’ e bağlı ilköğretim okullarında eğitim gören öğrencilerin bilgilerinin bu sisteme girilmesiyle başlayan bu süreçte, öğrenci ve eğitimiyle ilgili her türlü bilgiye kolayca erişim sağlanmıştır. Sistemde öğrencilerin kişisel bilgilerine ulaşma, not girişi, öğrenci devamsızlıkları, karne işlemleri, öğrenci kayıt ve nakil işlemleri, belgelerin güvenli bir şekilde iletilmesi, arşiv tarama, sorgulama ve arama gibi işlemler yapılabilmektedir. Yöneticiler okul ve öğrenciyle ilgili tüm işlemleri yaparak, öğretmenler öğrencileri her yönden değerlendirerek, veliler ise çocukları hakkında her türlü bilgiye ulaşarak e-Okul sistemindeki yerlerini almışlardır. İlköğretim okullarından sonra liselerde de kullanılmaya başlanan bu sistemin farklı modüller eklenerek daha da geliştirileceği ortadadır. Sistem kağıt israfını önlemiş, işlerin daha hızlı ve etkili bir şekilde yürümesini sağlayarak hem maddi tasarruf hem de zamandan tasarruf sağlamıştır. Bu tasarruflar göz ardı edilemeyecek düzeydedir.

Ancak böyle çok kullanıcılı bir sistemde, site tasarımı tüm kullanıcılara hitap edebilecek şekilde, kullanıcıların zorluk yaşamadan işlemlerini yapabilecekleri şekilde yapılandırılmalıdır. E-Okul sisteminin tasarımına baktığımızda pek çok kullanıcı tarafından anlaşılmayan bazı noktalar vardır. İşlem yaparken kullanılan simgeler ya da menüler çoğu kullanıcı tarafından anlaşılmamaktadır. Menüler karmaşık yapıda sıralanmış, hangi menüden hangi sayfanın açılacağı tahmin edilememektedir. Sistem içerisinde yardım, site içi arama, site haritası gibi bölümlere ihtiyaç duyulmaktadır. Ayrıca sistem server yavaşlığından dolayı her ara dönem ve dönem sonlarında yüklenmeye bağlı olarak kilitlenmektedir. Sistemde süre kısıtlaması da vardır. $10 \mathrm{dk}$. süre içinde bir işlem yapılmazsa sistem kullanıcıyı sistem dışına itmektedir. Bu da kullanıcıları, özellikle öğretmenleri olumsuz etkilemektedir.

Böylesine büyük bir kitleye hitap eden e-Okul sisteminde bu gibi hataların kullanıcılardan alınan dönütler ile düzeltilmesi gerekmektedir. Yaklaşık 7 yıldır kullanılan bu sistemde bir takım değişiklikler yapılmıştır. Fakat tüm kullanıcıların istedikleri işlemleri rahatça yapabilecekleri bir tasarım henüz oluşturulamamıştır. Kullanıcıların sistem hakkındaki düşünceleri dikkate alınır ve gerekli düzenlemeler yapılırsa kullanım sorunları ortadan kalkar ve sistem tam anlamıyla amacına ulaşılabileceği düşünülmektedir. 


\section{Öneriler}

MEB e-Okul sistemini kullanan öğretmen ve yöneticilere anket uygulayarak onların sistem hakkındaki düşüncelerini alabilir. Bu görüşler ışı̆̆ında tasarımcılar sistemde bazı değişiklikler yapabilir. Yaptığımız çalışmanın 1şığında aşağıda yapılabilecek değişimler sıralanmıştır:

- Sistem tasarımı daha basit yapıda, menüler ve kullanılan simgeler daha anlaşılır bir şekilde düzenlenmelidir.

- Kullanıcıların zamanlama problemleri yaşamamaları için süre sayaçları kullanıcının sistemde daha uzun kalabilecekleri şekilde ayarlanabilir.

- Sistemi kullanacak öğretmenlerin ve yöneticilerin teknolojiye olan uzaklıkları farklı ölçülerdedir birçok öğretmen ve yönetici bilgisayar okuryazarlığg konusunda sıkıntı çekmektedirler bu yüzden öğretmenlere ve yöneticilere sistem hakkında bilgilendirici seminerler verilebilir, var olanların kapsamı genişletilebilir.

- Sistemin yoğun kullanım seviyesine bağlı olarak kilitlenmesine karşı sunucuların ihtiyaçlarla orantılı olarak yazılımsal ve donanımsal güncellemelerinin yapılması ve diğer gerekli teknik önlemlerin alınması önemlidir.

- $\quad$ Siteye gelişmiş bir yardım modülü ile birlikte site içi arama, site haritası gibi bölümler eklenmelidir.

- Veri girişlerindeki sorunları en aza indirmek için sisteme ofis programlarında hazırlanmış dosyaların içeriklerinin aktarılmasının mümkün kılınması yararlı olacaktır.

- Sistemin offline olarak da kullanımına olanak tanıyan eklentiler ve programlar geliştirilebilir. Böylelikle internet bağlantısı kaynaklı birçok sorunun önüne geçilebilecektir.

- Verilerin her defasında yeniden girilmesi yerine daha önceden kaydedilmiş veriler üzerinde yapılacak güncellemeler ile işlemler daha da hız kazanabilir.

- Sistemde bulunan bazı modüller geliştirilebilir. Örneğin; rapor alma modülünün geliştirilmesi gerekmektedir.

- İleride bu sistem ile ilgili yapılacak çalışmalarda sisteme eğitim-öğretim etkinlikleriyle ilgili eklenebilecek bazı modüller üzerine çalışılabilir. 


\section{Kaynakça}

Acartürk, C. \& Çağıltay K. (2006). İnsan Bilgisayar Etkileşimi ve ODTÜ'de Yürütülen Çalışmalar. Akademik Bilişim 2006 Bildiriler Kitapçığı, 9-11 Şubat 2006, Denizli.

Altıntaş, H. (2002). Sanal bürokrasiden e-devlete teorik yaklaşımlar. http://www. bilgiyonetimi.org/cm/pages/mk1_gos.php?nt=237 adresinden 23 Ocak 2009 tarihinde alınmıştır.

Aysin, Ş. (2007). E-kurum dönüşüm stratejileri ve MEB 'nın e-devlet uygulamalarının ögretmenler tarafindan değerlendirilmesi. Yüksek Lisans Tezi, Gazi Üniversitesi, Eğitim Bilimleri Enstitüsü, Ankara.

Çağıltay, K. (2005). E-dönüşümü kullanabilmek? İnsan bilgisayar etkileşimi, kullanılabilirlik ve e-devlet projeleri. 2. Polis Bilişim Sempozyumu, 14-15 Nisan, Ankara

DPT. (2005). E-devlet proje ve uygulamalart. http://www.bilgitoplumu.gov.tr/yayin/e DevletProjeveUygulamalari.pdf adresinden 23 Ocak 2009 tarihinde alınmıştır.

DPT. (2006). Bilgi toplumu stratejisi.http://www.bilgitoplumu.gov.tr/btstrateji /Strateji_Belgesi.pdf adresinden 23 Ocak 2009 tarihinde alınmıştır.

DPT. (2006). E-dönüşüm Türkiye projesi’nin amaçları ve yapılan çalışmalar. http://www.bilgitoplumu.gov.tr/edtr.asp adresinden 24 Ocak 2009 tarihinde alınmıştır.

Karasar, N. (2008). Bilimsel araştırma yöntemi: Kavramlar, ilkeler, teknikler. Ankara: Nobel Yayın Dağıtım

Krippendorff, K. (2011). Communication Methods and Measures 5, 2,1-20.

MEB. (2007a,b,c,d). http://projeler.meb.gov.tr/pkm1/index.php?option=com_content\&view= category\&id=38\&Itemid=78 adresinden 21 Aralık 2008 tarihinde alınmıştır.

Neuendorf, K. A. (2002). The content analysis guidebook. Thousand Oaks, CA:Sage.

Nielsen, J. (1994). Ten Usability Heuristics. http://www.useit.com/papers/heuristic/heuristic list.html adresinden 26 Ocak 2009 tarihinde alınmıştır.

Oğuz, E. (2006). Web Tasarımı. http://yunus.hacettepe.edu.tr/ esino/ bilgimerkezi website.ppt adresinden 26 Ocak 2009 tarihinde alınmıştır.

Yılmaz, C. (2000, Şubat). Web Organizasyonu ve Tasarım. UlakNET Kurumsal Kullanıcıları Toplantıs1, Isparta Süleyman Demirel Üniversitesi. 